\title{
The Goldberg Variations 1: assessing the academic quality of multidimensional linear texts and their re-emergence in multimedia publications.
}

\section{Introduction}

For at least 90 years there have been attempts to produce intellectual work using media other than the traditional academic paper. Already in the 1920 s filmmakers tried to use film as a medium for intellectual reflection and argument, and from the 1960s onwards filmmakers like Rouch, Marker and Godard attempted to revive this. Overall their films have remained exceptional moments in the history of the medium. Film was an expensive medium, of course, and that may have contributed, but today's digital media are much more accessible, and many young scholars working in universities are drawn to using them, yet institutional recognition is slow in coming.

The history of film criticism in academia demonstrates the long and interactive process associated with the emergence of a canon of referential criteria, by which the scholarly community now addresses film. These criteria sought to understand the language of cinema, and explore the interplay of technical production, with the creative manipulation of content. With the emergence of well-developed multimedia projects by scholars or teams who wish to claim them as new ways of creating and communicating knowledge, the academic publishing world is confronted by many issues. Some are technical but perhaps the most challenging relate to these referential criteria, and the development of 
an agreed, shared, comprehensible and applicable set of criteria. In particular there is a great difficulty in combining both an analysis of content and scholarly argument, with an appreciation of the technical complexities, and the cyber-language that has emerged (in retrospect) over recent years (Author, 2009).

Intellectual work should be understood as occurring within a dynamic political economy in which the value of knowledge is in part determined by its transformation into exploitable capital. This insight alerts us to look for the institutions that participate in such transformations, and to deconstruct their practices in search of the application of power. The emergence of digital communication today confronts academic institutions with potentials that did not previously exist, and that they cannot easily contain by established institutional practices.

Earlier work on the application of digital media to the humanities and social sciences in Australia and North America revealed some of the embedded power structures that inhibit innovation. Author (2007) interviewed creative innovators and younger scholars with histories of innovation in the use of digital media, and identified journals publishing digitally innovatory research papers/projects. His study revealed how the publishing process in a competitive academic environment reflects the often gerontocratic hierarchies of control, the reproduction and reinforcement of well-established systems for assessing value in publishing (peer review), and the pressures to conformity to established practice imposed on younger scholars. Such a dynamic stymies innovation 
and corrals scholarship in the space dominated by the traditions of disciplines and publishing.

Traditional journals that had attempted to introduce hypermedia publishing provided the initial stimulus for its development, though the driving force behind the innovation clearly came from a small group of scholars whose names reappear in the few journals that attempted such exercises. The first experiment took place in the heartland of US scholarship, the American Studies Association's American Quarterly, published in 1999: early in the life of the World Wide Web, and well before the innovations associated with Web 2.0. As the guest editor, the late Roy Rosenzweig, noted in his introduction on 'Hypertext Scholarship in American Studies' (http:chnm.gmu.edu/aq/hyperaq.html), it was time to move beyond the debate about the potential of such forms and try it out. $A Q$ invited proposals and ended up publishing four of them, using the emergent hypertext markup language and the linking and graphic opportunities it created. They were an interesting range of projects, from Louise Krasniewicz's Dreaming Arnold Schwarzenegger (an animated dream diary) to Thomas Thurston's hyperlinking project on photography and law. Afterwards $A Q$ published a debate about the pieces, but it has not engaged in further experiments of this kind. Rosenzweig, a celebrated historian and director of the Centre for History and New Media at George Mason University in Virginia, then tried to move the leading journal American Historical Review to a more adventurous position, However while he was able to point it towards some innovatory digital history research and web projects, the $A H R$ has not so far published any interactive projects directly. According to both Rosenzweig and American Historical 
Association Assistant Director Robert Townsend (interview, 2004), the major problem was that there did not exist a cohort of historians competent to referee such projects, to tease apart the historical content from the creative and information technology design and thus to assess the value of each in their synergistic presentation

The institutional issues were becoming clear. While younger scholars were keen to pursue digital publication, there were few if any avenues for doing so and there was little or no recognition of its value among peers. In fact there were few if any peers who had any competence to judge interactive publications, and thus a vicious circle of marginalisation reinforced the barriers to innovation. It would have to take a major leap of faith, combined with resources and creativity, to overcome these barriers. The University of Southern California's Vectors, Journal of Culture and Technology in a Dynamic Vernacular, first published online in 2005, pointed to what was required. Some years before, Francis Ford Coppola had visited USC and discussed with the President of the University the critical role that 'digital literacy' would have to play in the future of college graduates. The University had recognized the importance of this insight and committed major resources, opening an Institute for Multimedia Literacy, and then supporting the development of Vectors. Vectors' editor Tara McPherson (both a multimedia artist and a historian) and her colleagues drew on the lessons and frustrations from earlier experiments and recognized that three problems would have to be resolved (1) projects might stand alone on the web but they would have to be 'wrapped' in scholarly texts and exegeses to receive recognition, especially for tenure; (2) there would have to be a systematic development of peers capable of reviewing such projects for both 
their scholarly and digital qualities and in particular in relation to the syncretic production of knowledge they allowed, and (3) there would need to be resources committed to the development of digitally powered analytical frameworks to leapfrog the reinforcement of traditional antipathy to non-linear scholarship as demonstrated in traditional journals. The critical question that underpinned McPherson's strategy for Vectors remained that of quality - what criteria would be accepted by the wider peer community? What would be the currency in which the value of these multimedia essays would be judged?

It is this work we seek to build on, and these issues we seek to develop further in this paper. In particular we would like to overcome a now untenable opposition in which intellectual work in the old medium of densely printed pages tends to be judged only for its content, and work in new media only aesthetically, only for its form, as if writing is the only medium for reasoned argument, while other media can only appeal to taste and aesthetic pleasure. We seek to undo that distinction and look at content as well as form at what is said and how it is said as well as how that engages the reader, viewer or user, and we will do this with regard to both the older, static form of academic publication, and the newer, non-linear and interactive form. We do not see why emotion and intellect, insight and pleasure, should be separate and why the scholarly and the poetic cannot live side by side, acting upon each other without losing their distinct virtues and values.

To pursue these aims, we will look at two texts dealing with the same subject and produced by the same author, David Theo Goldberg, the one static, the other non-linear and interactive. The former is a scholarly article titled 'Deva-stating disasters - race in 
the Shadow(s) of New Orleans' (Goldberg, 2006), published by the W.E.B. Du Bois Institute for African and African American Research in their scholarly journal Du Bois Review, and following scholarly writing etiquette in all its details. The non-linear text is 'Blue Velvet - Re-dressing New Orleans in Katrina's Wake', which Goldberg produced with Stefka Hristova in the already mentioned online journal Vectors, Journal of Culture and Technology in a Dynamic Vernacular (Goldberg and Hristova, 2007). Both deal with the Katrina hurricane, an event which has become a major focus for American social science and humanities research, and both put forward very similar ideas and arguments, presenting Katrina as an event that revealed to which extent a new racism had come to underpin the fabric of American society, with devastating results for African Americans. We refer to these two pieces as the Goldberg Variations.

Our questions, therefore, are twofold. Firstly we ask, what is the intellectual and emotive content of each, what does each text have to say about the new racism and about Katrina, and secondly, how are the two texts structured and what intellectual and emotive work do their different forms and structures require from the reader or user? Such questions can of course be answered programmatically, and there already exists a great deal of debate on the affordances of non-linearity and interactivity. But, given the need to develop criteria for the peer review of digital academic publications, we feel that there is an urgent need for detailed case studies that not only show how non-digital and digital publications compare in terms of their academic content, but also critically evaluate how well concrete instances of digital academic use the potential of non-linearity and interactivity for the purpose of enhancing academic quality. What is needed now, is not further programmatic 
statements, but a set of case studies that documents the value of digital academic publication, both in terms of the traditional academic standards that continue to be valuable, and in terms of the new standards and new aspirations for academic work that non-linear, interactive publication can encourage and develop.

\section{Deva-stating disasters - a linear argument}

The Katrina Hurricane event has become a major focus for American social science and humanities research. A search of Google Scholar (31 Aug 2008) finds 2,900 "hits" for race, class and Hurricane Katrina, indicating the importance of the event as a marker of wider social relations in the USA of George Bush. For instance the journal Social Science Research published a special issue in June 2006 focusing on Katrina in New Orleans. In their examination of the results of a survey of 1200 survivors Elliott and Pais, sociologists at the local Tulane University, concluded that race and class had independent but exacerbating impacts on the experience of the event, and survival after it (Elliott and Pais 2006). Lavelle and Feagin (2006) pick up on this underlying question of race and/or class, proposing that the Hurricane Katrina events reveal much about White privilege and power in the USA. Even George Bush, they note, alluded to both racial discrimination and poverty as contributing factors to the intensity of the disaster and the failure of government responses in the aftermath. They also note that Bush's administration had done little to ameliorate racism, and had actually intensified poverty through its tax and welfare policies. 
It is in this context that Goldberg engages with Hurricane Katrina, and draws on his own and the research of others to pull out the key concepts to frame the analysis. The politics of interpretation of Hurricane Katrina are embedded in the broader arguments about race and class between conservatives, neo-liberals, liberals and the left. Once it was clear that poor and black people were the most damaged by Hurricane Katrina, and the least supported in recovery, the question turned to why? Conservatives would argue that the impoverished and inadequate culture of the black poor made them less resilient and resourceful in the face of disaster; neoliberals would propose that welfare dependency and a culture of crime and corruption in local government undermined the city's capacity to respond; liberals would point to the destruction of government capacity and the impoverishment produced by the welfare "reforms" of Republican administrations; while the left argued that generations of racism and White power had produced a lumpen proletariat abandoned by the state, emmiserated by capitalism, and suppressed by the police. The spaces into which they had been pushed over generations were the most vulnerable and the least protected parts of the city.

'Deva-stating disasters', Goldberg's traditional academic paper on Katrina, is structured as a singular argument, moving step by step to the conclusion that the 1980s saw a new 'born again racism' emerge (Goldberg also refers to it as 'racial Americanization'), which, while not enshrined in law, nevertheless had the same effect as the earlier segregationism which was enshrined in law, namely that the lives of black and white Americans are effectively segregated, and lived out under very different, and fundamentally unequal conditions. 
How does this argument unfold? Three brief paragraphs first set up the historical background, the move from the old 'segregationist' racism to the civil rights movement, and the tension that existed between the two in the post-War period, followed by the emergence of the new 'born again racism', or 'racial Americanization', in the Reagan era. Next, the key characteristics and effects of the new racism are described: (1) white resistance against 'special treatment' (affirmative action) in the name of equal treatment for all; (2) reduction of welfare (and emergency) programs and increase of spending on 'state institutions of violence'; (3) a widening gap between white 'haves' and black 'have-nots'; and (4) increasing incarceration of the poor in prisons.

At this point, halfway through, Katrina is introduced. After a brief paragraph on New Orleans before Katrina (focusing on the poverty of the large black population and the poor quality of life in their neighbourhoods), the aftermath of the disaster is discussed, with it lack of medical and other assistance for the poor, and its militarization of emergency relief and use of Black Hawk mercenaries who in New Orleans behaved much the same as they had in Baghdad. Finally Goldberg evokes a future for New Orleans in which many blacks will not return and many black schools will not be reopened, and in which the city will change both culturally and politically. His conclusion reiterates the key characteristics of the new racism and concludes that the events in New Orleans demonstrated all these characteristics, and their devastating effect on the majority of African Americans. 
A text of this kind has a number of characteristics. Firstly, like the most common types of Western narrative, it moves in linear fashion towards a resolution, a climax, a conclusion. To understand the text, readers must to some extent 'suspend disbelief', hear the writer out to the very end, before being able to take stock and start critically reflecting on what they have read. Even typographically the text provides no pauses, no white spaces for the eye to rest and the mind to reflect. Yet the obligatory abstract ensures that the paper's conclusion is foregone. While the 'abstracts' of stories (Labov, 1972) do not give the resolution away and serve only to entice the reader into the story, the abstracts of academic articles turn the paper itself into an elaboration of something already said, rather than the gradual exploration and unfolding of an idea.

Secondly, the focus on a singular 'thesis', requires that the various themes Goldberg engages with (for instance, 'active segregation', 'militarization', 'incarceration') must be hierarchized, for instance by presenting them as 'factors' or 'elements' that are overarched by, and subordinated to, the single theme of 'racial Americanization'. Only the obligatory list of key words simply lists the themes as equal in value, but many of Goldberg's themes are not included in the list.

Thirdly, the paper clearly positions itself within the literature on racism and the debate on Katrina that followed the disaster (cf e.g. Elliott and Pais, 2006; Lavelle and Feagin, 2006, and the June 2006 issue of Social Science Research). However, because the flow and pace of the argument cannot be interrupted by too much explanation and documentation without losing its force (as a social scientist, using the Harvard system, 
Goldberg does not use footnotes), referencing, documenting and explaining remains to a large extent restricted to bracketed references and selected factual material such as the statistics in this passage (Goldberg, 2006: 89):

The fate of New Orleans in the wake of Hurricane Katrina in late summer 2005 illustrates these trends with furious force. A city of almost half a million, its population when the hurricane hit was $67 \%$ African American. One in eight Americans, and double that proportion of Black Americans, now live in poverty. In New Orleans, the poverty rate for Black residents was closer to $50 \%$, as a result of the multiplying logic of high racial concentration which Nancy Denton (1994) has identified more generally.

Overall, the reader is addressed as already familiar with the factual and historical details, and percentages are mentioned in passing rather than presented in tables. When Goldberg refers elsewhere to 'the series of Supreme Court rulings from the late 1940s', the definite article suggests familiarity with the whole of this 'series' and no further historical documentation is provided. .

However, what should not be assumed is that traditional academic papers cannot have an emotive or poetic element. Goldberg's descriptions of the aftermath of Katrina are writerly, vivid and gripping (2006: 90)

Family and other networks could support the mobile, while the immobile were left to flounder on a flooded and rotting city, many losing contact even with the family members sharing their fate. The least lucky lost their lives. The wealthier watched from afar, while the poverty-stricken shared the streets with floating bodies (sometimes of their own relatives), excrement and oil pollution 
As a South African refugee from Apartheid, a one time documentary filmmaker now heading the University of California's Humanities Research Centre, Goldberg brings a creative writer's sensibility to the systematic analysis of social and racial power, and demonstrates that the intellectual and the emotive can go together, also in a traditional academic paper.

\section{Blue Velvet: a non-linear mosaic}

"Blue Velvet" is clearly a project of Left scholarship. Vector editors Tara McPherson and Steve Anderson integrate both social and media critique when they say in their introduction to Goldberg's multimedia piece, that "the tragic events that unfolded in New Orleans and along the Gulf Coast were possible precisely because of years of neoliberal policies that underwrote the necessary conditions for such devastation in the first place...The poetic pace and haunting spaces of "Blue Velvet" take us closer to that truth than any evening spent with CNN."

(http://vectorsjournal.org/index.php?page=7\&projectId=82).

The Italian poster for David Lynch's 1986 movie "Blue Velvet"/ "Velluto Blu" has Isabella Rossellini bent backwards and stretched out in a stocks, her stockinged and gartered legs splayed, and her crotch facing the viewer. We cannot see her face. The light is blue. 
Quick Time ${ }^{\mathrm{TM}}$ and a
TIFF (Uncompressed) decompressor

are needed to see this picture.

In Australian racist slang Black Velvet refers to Aboriginal women and their sexual availability. What is "Blue Velvet" doing as the title of David Goldberg's multimedia social commentary on race and class in New Orleans before and after Hurricane Katrina?

In the original film Bobby Vinton's song "Blue Velvet" is played; especially important are the lyrics:

Ours a love I held tightly

Feeling the rapture grow

Like a flame burning brightly

But when she left, gone was the glow of

Blue velvet

Lynch uses a candle flame throughout the film as emblematic of danger and safety: the brighter the flame, the safer the protagonist; when it splutters or dies then danger lurks. Blue Velvet then seems to refer to power and safety in a space riven by threats of violence and darkness. New Orleans? 
The online multimedia project by Goldberg makes reference to the Lynch film and thereby to the Vinton song. Blue Velvet presents 24 chapters (called 'arguments' in the Index), each on a separate page, with titles such as 'Redlining', 'Politics of Fear', and 'Crisis Management'. The titles represent the key theoretical concepts Goldberg will use to come to an understanding of Katrina, and they are much the same as in the traditional paper, but here they are not hierarchized, and, although numbered, can be accessed in any order.

\section{INSERT FIGURE 1 ABOUT HERE}

Figure 1: Blue Velvet interface screen

The way in which these chapters are accessed shows that in this case there is no 'abstract', no foregone conclusion. On top of the interface screen (see figure 1) the numbered titles of the 'arguments' scroll from left to right, and when one of them is clicked, a key phrase appears in red lettering in the centre of the screen (e.g. 'immobility', 'structural racism', 'homogenized apartness') and nouns start descending from the top, sometimes singly, sometimes in clusters. The 'activist segregation' argument, for instance, triggers the following nouns: 'town', 'city', 'voting practice', 'law', 'culture', 'economies', politics', 'active intervention', 'neighbourhood', racial' covenants' and 'redlining'. The user therefore first encounters isolated concepts and ideas which are literally and figuratively 'in the air' in relation to New Orleans and Katrina, and which are presented as incentives and pointers for reflecting before they lock into place into a coherent argument. They are seen against the background of three silhouettes 
of New Orleans, vertically ordered in terms of distance and colour saturation, with the top layer the most distant and pale, the bottom layer the closest and most saturated, and against a soundtrack of violently wooshing water. The screen therefore presents the key words and phrases against the background of an image of the city and of the sound of the disaster

Still on the interface screen, clicking on the key phrase of any of the 'arguments' triggers a tilt down in which the key phrase impacts with the force of a bomb on the silhouette of New Orleans. As soon as this happens, the background darkens to a black in which users can only just discern an aerial view of New Orleans, now engulfed in blackness, and various 'morphemes' from the key phrases which briefly hint at possible interpretations, e.g. 'trap' and 'apart' in the case of 'homogenized apartness'. Only then do the cascading nouns and morphemes congeal into a text, in the upper part of the screen (see figure 2). Here, for instance is the text that relates to the 'activist segregation' keyword:

Activist segregation involved active intervention in politics, law, economics, and culture, self-consciously designed to produce segregated cities, towns and neighbourhood spaces. It reproduced the work of racial covenants and redlining. It promoted residential segregation. The closed doors of segregated schools and colleges and inaccessible workplaces. All-white city halls and legislatures. Segregationalistally apportioned voting districts. Racially defined and determined Americans came to live largely in different cities, racially designed, consigned, resigned.

As Goldberg himself has explained it (interview, 2008), the key phrases, "when dropped in water, dissolve into their constituent etymologies, eventually causing the text of a related argument to appear". 


\section{INSERT FIGURE 2 ABOUT HERE}

Figure 2: Blue Velvet chapter screen

Traditional documentaries often began by showing documentary images, perhaps accompanied by music, and the explanatory voice over would enter only after viewers had had a chance to observe for themselves the world portrayed by the documentary. In contemporary current affairs television, the anchor's authoritative interpretation tends to precede such images of evidence, and such 'on the spot' reporting, as might follow. Blue Velvet most resembles those earlier documentaries. It gives users a chance to think for themselves before the voice of Goldberg enters. Yet the structure of their exploration is held together by Goldberg's sense of the elements needed to build both the specific arguments and the larger structure in which they come together, the structure of Blue Velvet as a whole.

The chapters are neither hierarchized, nor linear. Each appears in the same format, each is given the same visual weight, and each is accompanied by archival documentation in ways we will discuss in more detail below. They are also non-linear. They can be accessed by the user in any order. Even when viewed in the order suggested by the chapter numbers, the result is not a singular line of argument, but a mosaic of the kind that Bill Nichols (1981: 211-2) described in relation to the films of Frederick Wiseman:

The whole is not organized as a narrative, but more poetically, as a mosaic; only the parts have diegetic unity and between sequences editing seldom establishes a chronological relationship. (...) Lacking narrative structure, Wiseman's films also lack linear-causality explanation of events. They do, however, imply a theory of 
the events they describe - one consonant with a mosaic structure and at variance with a model of linear causality (...) It assumes that social events have multiple causes and must be analyzed as webs of interconnecting influences and patterns.

The structure of Blue Velvet clearly brings out that its non-linearity is not just a different format for the same content, but expresses a different and more appropriate analysis of its subject matter, and one which is much more difficult to realize in the traditional linear format of academic papers.

A brief overview of Blue Velvet's 24 chapters in the order of their numbering will demonstrate more clearly how Goldberg has assembled this mosaic structure. It should of course be remembered that users do not have to access the tesserae of the mosaic in this order.

\section{New Orleans}

This chapter characterizes New Orleans as "on the surface the most non-American of US cities", and a threat to America's self image, a place where "morals are vulnerable to local lust, language to foreign inflection and alien custom, foodways to the spicy attraction of gumbo ingredients (...) and racial 'purity' to every mixture available"

\section{Preferences}

Following the vivid description of New Orleans, this chapter presents a more abstract argument, arguing that the State structures the conditions in terms of which choices can be made. It has no direct link to the preceding chapter, but contrasts with it in style and substance, as a different kind of facet for the mosaic. 


\section{Homogeneity}

This chapter continues from Preferences, arguing that, today, choice is only apparent and has been 'privatized', "circumscribed to the limitations of one's private circle"

\section{Activist segregation}

This chapter introduces another kind of 'facet', a snippet of historical background, showing that racially segregated neighbourhoods were actively created in the 1930s: "racially defined and determined, Americans came to live in different cities, racially designed, consigned, resigned"

\section{Redlining}

This chapter continues the historical discourse, showing how neighbourhoods were ranked in terms of their desirability for residential investment, and how this practice was actively supported by Government in the 1930s.

\section{Conservationist segregation}

This chapter explains the concept of 'conservationist segregation': de facto segregation continued after formal structures were lifted, as the root causes were not addressed.

\section{Racial privacy/privatizing race}

This chapter shows that neoliberalism privatized racism, reduced welfare (and emergency) programs and increased spending on prisons and the military. 


\section{Catastrophy}

This chapter introduces some of the social problems in New Orleans and argues that natural disasters become social disasters "exacerbated by the circumstances of their enactment"

\section{Apparition}

Continuing the theme of the previous chapter, this chapter argues that "catastrophes are pre-announced by apparitions haunting the urban landscape."

\section{Political fear}

This chapter returns to the theme and style of chapter 1, evoking New Orleans in poetic terms: "shimmering solicitation, the sparkling city (...) inviting visitation, carnival revelry, unselfconscious excess..."

\section{Crisis management}

This chapter discusses the ways in which crisis management tries to limit the unraveling of the social fabric that tends to follow crises.

\section{Emergency}

This chapter shows how emergencies bring in the force of law.

\section{Carcerality}


This chapter describes America's prison system as a "long term parking place for the poor" without direct reference to New Orleans or Katrina.

\section{Exposure}

On an equally general footing, this chapter argues that catastrophic events reveal social vulnerabilities and inequalities

15. Violence

This chapter presents an abstract argument not directly related to Katrina or New Orleans, defining violence as 'leaving transforming marks'

\section{Skin}

This chapter returns to the theme of segregation and relates it to Katrina, which has "embodied and exemplified life on the frontier of skin", and revealed the restrictions of choice related to skin.

\section{Mis-recognition}

This chapter presents another theoretical argument about violence, which, Goldberg says, may calculate its outcome, but rarely considers the disruption it will cause in people's lives. 


\section{Surviving}

This chapter is a descriptive piece about rebuilding the city: "Storms come and go. They uproot trees, blow down telephone and power wires, wrestle loose roof tiles, rattle windows and shatter glass ... Once the wind is spent and the rain has moved on, pieces are picked up and the slow, steady work of rebuilding and replacement takes over"

\section{Militarization}

This chapter returns to the earlier argument that in neoliberal states emergency work can only be done by the military, as a result of which the city of New Orleans entered a 'carceral condition'

20. In-security

This chapter returns to the theme of New Orleans as a 'non-American' city, lying low and exposed to water, and, at Carnival time, "borne by liquid of another kind"

\section{In-visibility}

This chapter continues the theme of New Orleans as "the perennial anomaly, "a democratic city in a sea of redness, of sexual outness surrounded by Bible-belted constraint and constriction"

\section{Disenchantment}

This chapter flashes back to an event in 1866, a riot against 'multiracial alliance' in which forty blacks were killed 


\section{Singing the Blues}

This chapter summarizes Goldberg's key point: New Orleans was driven into deepening segregation, and Katrina 'ripped open' the way this was covered up.

\section{Redress}

This chapter describes what it will take to rebuild New Orleans: "Making homes out of housing, replacing schools to anchors revitalized neighbourhoods left for flat dead, making work for the return of souls lost". A song is then quoted : "Goin' back home... Goin’ back to New Orleans"

Although, read in this order, chapters 23 and 24 clearly provide a sense of conclusion, the whole remains a mosaic of heterogeneous and contrasting elements. Snippets of narrative and evocation as well as abstract theoretical arguments, and generalizations as well elements relating specifically to Katrina, alternate and are distributed in a discontinuous manner throughout the work, without any explicit logical connection, and yet with clear thematic unity.

It should again be remembered, of course, that these chapters can be accessed in any order. In addition the index (http://vectors.usc.edu/issues/05_issue/bluevelvet/prjindex/) brings the nouns and key phrases together differently, in the form of a star diagram with the key phrase in the centre (see figure 3). This, again, and perhaps even more strongly, 
suggests a multi-dimensional complementariness between concepts in relation to central concepts, rather than linear causality.

\section{INSERT FIGURE 3 ABOUT HERE}

Figure 3: Blue Velvet index

\section{Blue Velvet: documentation}

Every one of the 24 chapter screens we have just described presents not only an argument, but also, at the bottom of each screen, a sequence of pictures in soft sepia, the colour of historic evidence. Clicking on them produces statistics, historic photographs, audio quotes from Nagin, Bush and others, and brief video clips. Most often these materials provide evidence for the claims made in the text presented on the same screen. In the case of Redlining, for instance, we see 1930s maps of New Orleans showing the percentage of African Americans, Hispanics, Asians and Whites living in different parts of the city, with superimposed quotes from 1930s documents such as "Area D-35 and D36 are comparable, both consisting of old double and single cottages, poorly maintained, $10 \%$ of the population foreign born and $30 \%$ coloured, all being in lower income groups ...White slum clearance project LA-1 is located in area D-35." As a result Blue Velvet supports its arguments much more fully with statistical and historical documentation than the 'Deva-stating disaster' paper. It should of course again be remembered that users need not access these materials and are free to just read the arguments. 
The archival materials, however, do not only function as evidence for the arguments presented on the same screen. They also contribute to the mosaic structure, alternating different kinds of materials, and sometimes independently reiterating themes from other chapters that appear to contrast with the material presented in the argument that accompanies them. In Emergency, for instance, the argument about emergency bringing in the force of law is accompanied by three additional materials, (1) a document plotting the degree to which different classes of inhabitants were able to get away from New Orleans after the disaster, (2) archival photos of discriminatory signs, and (3) a table showing the number of car owners in various New Orleans districts. In Preferences the abstract argument about choice is accompanied by a document showing how white and black people in New Orleans perceived the amount of white and black people who stayed behind after Katrina, as well as a document on the effects of Bush tax cuts. There is a link but it is not immediately obvious and requires some reflection on the part of the user.

\section{Blue Velvet: time for reflection}

In our discussion of 'Deva-stating disasters', we suggested that traditional academic papers require from their readers a kind of 'suspension of disbelief' which, if the argument is to be fully understood, must be kept up until the very end. Interactive digital publications can be very different in this respect. Not only are Blue Velvet's 24 chapters presented as self-contained screens, giving full and equal value to each 'facet' in the mosaic rather than subordinating them to an overarching explanation, but also, the only 
way to exit the chapters is 'up', back to the interface screen, from where the next element must be chosen. As a result there is always a pause between the chapters, a moment of reflection after which a new choice will have to be made.

The link between the chapters is never explicitly made and must therefore be provided by the user. Gone is the profusion of explicit conjunctions, the 'however's', the 'in additions', and the 'therefore's' which have increasingly characterized academic discourse ever since the days when John Locke called for their greater use and wrote that "a man must have words to show what connexion, restriction, distinction, opposition, emphasis \&c he gives to each respective part of his discourse" (1972 [1706]: 72). Today it is the user who makes the connections, yet the whole is still held together by Goldberg's vision of the theoretical and documentary resources necessary to make sense of contemporary racism and its relation to the events in New Orleans.

\section{Blue Velvet: multimodality}

How does Blue Velvet use the multimodality of its medium? We have already seen how the interface screen superimposes theoretical key words on a visual evocation of New Orleans, and how the disaster itself is signified by the sound of violently wooshing water, by the sudden, dramatic impact of the user's click, and by a dramatic darkening of the image. We have also noted the richness and variety of the archival material Flash Media allows - tables and charts, as well as photographs and audio and video clips. 
Several other examples can be noted. As the main texts of the chapters appears on the screen, for instance, the sound of the fury of the flood crosses into an orchestra of African drums and vocalizations which literally 'drums in' the message and also lends it an African-American flavour. And the typography of the texts is deliberately irregular in size and setting, reminding of handset activist leaflets, and therefore signifying the texts as political statements that are meant to provoke and to stir readers into action (see figure 2).

Clearly the at times poetic and impassioned writing of Goldberg, and the audiovisual design of Blue Velvet, help to blend the intellectual and the emotive, the analytical and the poetic. But the design of Blue Velvet is not just an aesthetic embellishment, it also helps express Goldberg's sociological argument, for instance by allowing simultaneity, so that we can at once grasp a theoretical argument and remember that it is made in the context of Katrina, or in the context of a concern with African Americans. Blue Velvet's design explores new ways of making "connexions" between the "respective parts of discourse", and in is "in the right use of these that more particularly consists the clearness and beauty of a good style", to quote Locke again (1972[1706]: 72)

\section{Conclusion}

Comparing a linear and a non-linear text, we have been able to identify some of the ways in which non-linear texts can add value that has a direct bearing on the academic quality 
of the text and can therefore contribute to building a set of criteria to help peer reviewers assess digital publications:

- Digital publications allow complex, multi-factor understandings of social events, provided the elements they present are well chosen and adequate to the subject matter.

- Digital publications can combine incisive argument with much more extensive and detailed archival and documentary evidence than traditional linear texts, which often argue their points on the basis of a much more selective and restrictive set of examples

- Digital publications can simultaneously present a 'foreground' and a 'background', for instance to ensure that a given argument is read against the background of a specific historical, political or social context.

- Digital publications can make use of typography and visual composition to provide elements of a text with specific textual identities such as 'main argument' and 'supplementary documentary material', thus providing clear connections between different textual elements 
- Digital publications can make use of typography to mark the modality of a given textual element as, for instance, a piece of political activism (e.g. 'handset leaflet look'), or a piece of historical evidence (sepia).

- Digital publications are not just interactive in allowing choices to users, but also, and more importantly, in providing 'pauses', 'gaps' in which users can reflect on the connections between the various ideas and items of information presented by the text.

- Digital publications can enhance emotive engagement beyond the tools of creative writing, and productively bring the traditions and creative resources of documentary filmmaking to bear the production of academic texts.

More generally, Blue Velvet challenges simple narratives and claims to a single explicable truth about the social world. Arguing for readers who stop, go back, reflect and then create their own synthesis, it challenges the benefits of linear narratives with clear openings and endings, proposing instead that allusions, evocations and emotional explorations also convey understanding, or at least stimulate interrogative minds to deeper reflection.

The social world which Blue Velvet exposes is multi-layered, complex, fragmented, yet interconnected. It is created in our minds through exposure to media and everyday stories, even though it is structured by processes we cannot see in ways that we do not normally comprehend. Goldberg has sought to show the "tear in the social fabric that 
turns natural occurrences into social disasters, catastrophes...the catastrophic event is preconditioned and so pre-ordained by decades of invisibility, instability, ineptitude" (2007: 8, Catastrophe). The medium of Flash Multimedia has enabled him to reveal the invisible, disinterring it from archives, associating separate elements with each other, bringing the ancient and the modern together, and confronting us with documentations that tell the story in graphic form. And he has alerted us to the instability, the floating words that decompose at a touch, the concepts that ripple off into associated thoughts, some sensible, some less so. In all these ways Blue Velvet has made a substantial contribution, both to our understanding of racism and of the events in New Orleans, and to the development of a new and, we believe, superior form of academic publishing.

\section{Thanks}

We thank David Theo Goldberg for agreeing to be interviewed about the Blue Velvet project. See video at http://www.vimeo.com/1901648 and interview transcript at http://wp.me/PeSc5-n.

\section{References}

Elliott, J. and Jeremy Pais, J.( 2006). "Race, Class, and Hurricane Katrina: Social

Differences in Human Responses to Disaster.” Social Science Research 35: 295-321.

Goldberg, D.T. (2006) 'Deva-stating disasters - Race in the Shadow(s) of New Orleans', Du Bois Review 3(1): 83-95 
Goldberg, D.T. and Hristova, S. (2007) 'Blue Velvet - Re-Dressing New Orleans in Katrina's wake', Vectors, Journal of Culture and Technology in a Dynamic Vernacular, Fall 2007 http://www.vectorsjournal.org

Jaffé, H.L.C. (1967) De Stijl, New York: Harry N. Abrams Inc

Author, A. (2007) "Bridging the Mire between E-Research and E-Publishing for Multimedia Digital Scholarship in the Humanities and Social Sciences: An Australian Case Study “, Webology.ir/2007/v4n1/a38.html,

Author, A. (2009) "Beyond the static text: Multimedia interactivity in academic publishing (not)," In: B. Cope and A. Phillips (editors). The future of the academic journal. Oxford: Chandos.

Kress, G and Author, T. (2006) Reading Images - The Grammar of Visual Design. $2^{\text {nd }}$ edition. London: Routledge

Labov, W. (1972) 'The Transformation of Experience in Narrative Syntax', in W. Labov Language in the Inner City, Philadelphia: University of Pennsylvania Press.

Lavelle, K. and Feagin,J. (2006) "Hurricane Katrina: The Race and Class Debate." Monthly Review 58(3).

Locke, J. (1972[1706]) An Essay Concerning Human Understanding, Vol II, London: Dent 